Viso - Cadernos de estética aplicada Revista eletrônica de estética

ISSN 1981-4062

No 11, jan-jun/2012

http://www.revistaviso.com.br/
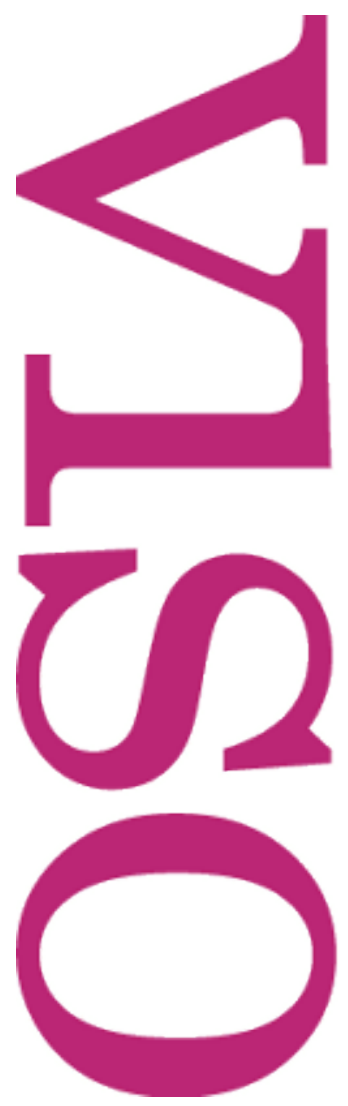

\title{
Estética da arquitetura, Kant e Niemeyer: aproximações em investigação Miguel Gally
}

Universidade de Brasília (UnB) 
GALLY, M. "Estética da arquitetura, Kant e Niemeyer: aproximações em investigação". In: Viso: Cadernos de estética aplicada, v. VI, n. 11 (jan-jun/2012), pp. 61-70.

DOI: 10.22409/1981-4062/v11i/121

Aprovado: 02.09.2012. Publicado: 07.09.2012.

(C) 2012 Miguel Gally. Esse documento é distribuído nos termos da licença Creative Commons Atribuição-NãoComercial 4.0 Internacional (CC-BY-NC), que permite, exceto para fins comerciais, copiar e redistribuir o material em qualquer formato ou meio, bem como remixá-lo, transformá-lo ou criar a partir dele, desde que seja dado o devido crédito e indicada a licença sob a qual ele foi originalmente publicado.

Licença: http://creativecommons.org/licenses/by-nc/4.0/deed.pt_BR

Accepted: 02.09.2012. Published: 07.09.2012.

(C) 2012 Miguel Gally. This document is distributed under the terms of a Creative Commons Attribution-NonCommercial 4.0 International license (CC-BY-NC) which allows, except for commercial purposes, to copy and redistribute the material in any medium or format and to remix, transform, and build upon the material, provided the original work is properly cited and states its license.

License: http://creativecommons.org/licenses/by-nc/4.0/ 


\section{Pressupostos e introdução}

Investigar algumas obras (de arte) arquitetonicamente, ou seja, espacialmente, levando em conta seu desenho e seu caráter público sem recorrer a uma consciência histórica forte, é o que propomos como exercício de pensamento a partir da estética crítica do belo. A aproximação em questão se dará entre um arquiteto pensador - Oscar Niemeyer - e um pensador (esteta) da arte - Immanuel Kant - para os quais a liberdade é condição da vida dos homens e não apenas da estética, da arte ou da arquitetura.

O conjunto da obra de Niemeyer inclui momentos variados que percorrem quase 70 anos de produção madura e vigorosa ${ }^{1}$ que vão desde o complexo da Pampulha (1940) passando pela experiência Brasília (1956-1962) e obras realizadas fora do Brasil na época em que foi exilado (como a sede do partido comunista em Paris, de 1965, ou a Universidade de Constantine, Argélia, de 1969) até os mais recentes Museu de Arte Contemporânea de Niterói (1991-1996) e a Torre Digital (2008-2012) nos arredores de Brasília. Falar desse conjunto com seriedade não é uma tarefa fácil e dificilmente encontrará respaldo unânime uma defesa ou acusação de sua (não) unidade, se levadas ao extremo seja uma única vertente teórica seja uma divisão radical da sua obra. ${ }^{2}$ Nesse conjunto, entretanto, há uma provocação para se pensar uma unidade, pois Niemeyer produziu obras que são públicas por excelência, não apenas enquanto distintas da escultura vista como mera expressão individual ${ }^{3}$ ou realizadas segundo uma intenção pública como é a Praça dos Três Poderes, 1958 (de caráter cívico) ou o Congresso Nacional, 1958 (de caráter deliberativo); mas sim, públicas como sendo obras que não podem ser desvinculadas do seu entorno, de sua vinculação com outras obras arquitetônicas e com a cidade, de sua vinculação com a natureza circundante e com as pessoas que a utilizam ou que por elas passam. E públicas, sobretudo, por causa da vinculação dessas obras com o pensamento.

Se é algo difícil falar de Niemeyer e do conjunto de sua obra arquitetônica por causa do seu longo percurso de produção, em Kant enfrentamos a mesma complicação, mas por uma carência de material: explicitamente e retirando os exemplos, Kant define a arquitetura em apenas um par de frases na sua Crítica da faculdade de julgar (1790). Para tornar possível uma aproximação entre esses dois pensadores, precisamos, antes de qualquer estratégia, recortar a produção do primeiro e explorar ao máximo, no segundo, as noções mais gerais que estão vinculadas àquele breve trecho que trata da arquitetura relacionando-o com sua estética crítica do belo e da arte em geral a partir do princípio da estética do gosto em associação à ideia estética.

Boa parte daquilo que Niemeyer fala de sua própria obra, não utilizaremos como base principal da nossa exposição; nem o que alguns críticos e estudiosos consideram como decisivo. Não por ser algo desimportante, e sim porque são considerações e reflexões muitas vezes carregadas de um pensamento reforçado por uma consciência histórica forte, a qual pretendemos minimizar nesta apresentação. Por exemplo, a leveza como 
elemento estético-perceptivo de diálogo com seu mestre e parceiro Le Corbusier"; as relações de a- ou dissociação entre os espaços interno e externo, bem como a da superação dos limites desses espaços, sendo muito ou pouco definidos; o uso das curvas e do concreto armado como quase princípios de suas obras e projetos (em diálogo com o ângulo reto); ainda, a relação transparência/opacidade são questões decisivas para qualquer investigação que enfatiza a consciência histórica, a técnica ou estilos contra e com os quais Niemeyer desenvolve sua arquitetura. Aqui, faço um esforço para uma leitura do tipo pós-histórica, tal como defende Danto, mas pensando não em uma discursividade presente no e a partir do modo como tais obras se apresentam, ou seja, a partir do que ele entendeu como significados incorporados [embodied meanings]. ${ }^{5}$ Pensando sim em uma relação estética não sentimental que tais obras em suas formas podem despertar e provocar. Tal leitura, no entanto, precisa ainda de uma estratégia para viabilizar a aproximação que se propõe, afinal sabe-se que as obras de Niemeyer esperam imprimir uma consciência política ${ }^{6}$ e Kant pensa uma estética que afirma um desinteresse frente a um conteúdo (ou conceito) determinado, entretanto em ambos os pensadores é uma política da liberdade que nos chama a atenção. Por isso, nesse sentido amplo, procuraremos enfatizar uma política da estética crítica kantiana e procurar obras arquitetônicas com peso político ideológico mínimo, embora saibamos ser impossível abdicar completamente de certo formalismo em Kant e de certa consciência política/ideológica nas obras de Niemeyer.

\section{Kant e a estética da arquitetura}

Tomo como ponto de partida algumas ideias de Kant ${ }^{7}$ para a aproximação em questão, embora ciente da complexidade que é pensar uma arte, tal com ele propõe: sem poder abrir mão da sua intencionalidade por ser sempre uma atividade da razão e do arbítrio (§43), mas que tal intencionalidade não pode servir de determinação no processo de criação (§45) nem de recepção (§2) da obra quando pensada desde sua beleza. A beleza entendida por Kant, não como algo que pertença ao objeto, é um sentimento originado pela conformidade a fins que algumas formas despertam ao colocar em marcha um jogo livre entre as faculdades de conhecer, entre a legalidade do entendimento e a fantasia da imaginação. O curioso e problemático para a arquitetura bela é que tal intenção, indispensável em qualquer arte bela, é nela ainda mais exposta, a ponto de limitar a possibilidade daquele jogo livre:

À plástica, como primeira espécie de artes figurativas, pertencem a escultura [Bildhauerkunst] e a arquitetura [Baukunst]. A primeira é aquela que apresenta corporalmente conceitos de coisas como elas poderiam existir na natureza (todavia enquanto arte bela com vistas à conformidade a fins estética); a segunda é a arte de apresentar conceitos de coisas que somente pela arte são possíveis e cuja forma não tem como fundamento determinante a natureza mas um fim arbitrário, com este propósito contudo ao mesmo tempo esteticamente conforme a fins. Na última, o principal é um certo uso do objeto artístico a cuja condição as idéias estéticas são limitadas (§51). 
Kant concebe a arte em geral como diferente da natureza por ser trabalho da liberdade entendida como arbítrio; no seu fazer, geram-se obras, enquanto na natureza os produtos seriam simples efeitos. A obra de arte bela é uma arte: A) diferente da arte mecânica, cujo fim ou eficiência da produção é o determinante no modo do seu prazer, o qual depende de um conceito, seja ele qual for (pois bom é "bom para"); B) e diferente também da arte estética do agradável, meramente pessoal e baseada no prazer da sensação, no preenchimento de uma carência sensível de maneira imediata, abrindo mão completamente do conceito. A arquitetura pensada como bela, e não meramente como arquitetura boa ou arquitetura agradável, é baseada numa percepção refletida, cujo prazer está numa relação que o espectador estabelece com a obra e sua forma quando reconhece as condições de uma conformidade a fins. Ou seja, permanecendo atento para os conceitos que aquela forma/figura aponta, sem fixar a direção ou finalidade sugerida por um fim determinado. Tanto em uma arquitetura boa (A) quanto em uma arquitetura agradável (B), é a intenção seu fundamento de determinação seja enquanto apropriada para seu destino e uso (A) seja enquanto apropriada para um prazer do encanto ou emoção privada $(B) .{ }^{8} \mathrm{~A}$ arquitetura bela está justamente no meio do caminho entre uma arquitetura boa e uma arquitetura agradável, porque mesmo tendo um conceito determinado ou um uso pode ser apreciada como se não tivesse um, sendo objeto de um juízo tão imediato quanto o juízo do agradável, com a diferença de ser conforme a fins. Se esses juízos de gosto (do bom ou do agradável) ajudam a entender a diferença da arquitetura bela frente a outras arquiteturas, é somente pela passagem ao tema da criação que se completa a investigação: e arquitetura bela, como arte bela, é "expressão de uma idéia estética" (§51).

A grande dificuldade de entender a que se refere tal expressão (expressão do quê? ${ }^{9}$ ) está justamente na presença de uma indeterminação necessária, numa noção de expressão que não vincula algo a alguma coisa determinável. Uma ideia estética "dá muito a pensar", diz Kant, é uma ideia da imaginação, uma intuição à qual nenhum conceito determinado corresponde. Ela permite que pensemos ser a forma daquilo que intuímos com a imaginação (associada à sensibilidade) muitas coisas determinadas, embora nenhuma delas possa esgotar a qual conceito tal forma efetivamente se conecta, sob pena de se perder ou de se interromper a experiência estética. Trata-se, portanto, de uma experiência reflexiva, porque compara a forma do objeto às nossas faculdades de conhecer ou representar em geral, sendo ao mesmo tempo uma comparação das forças dessas mesmas faculdades. O princípio da conformidade a fins estética (sem um fim determinado) serve tanto na arte quanto na natureza bela, porque nos dois casos o entendimento e a imaginação operam livremente. O que não pode acontecer quando fazem parte do processo de construção do conhecimento ou de reconhecimento das coisas se utilizando de conceitos empíricos. Quando Kant diz que a natureza bela tem de parecer arte, ele pensa que ela tem de parecer ter uma intenção, o que efetivamente a arte sempre tem de ter, embora não se possa conhecer efetivamente se há intenção ou não, por exemplo, se haveria efetivamente um fim/propósito último da natureza. Quando Kant diz que a arte bela tem de parecer natureza, ele pensa que a arte, embora tenha 
uma intenção, não pode parecer ou transparecer tal intenção ou regra, assim como acontece quando julgamos ser bela a natureza. De modo que é a imaginação, uma faculdade em nós, que ativamente entra em cena e remete a um fim/conceito ou uso qualquer enquanto o entendimento não determina os objetos através dos conceitos de que dispõe. No caso da natureza bela, por não se saber se há alguma intenção, a imaginação precisa da faculdade de entendimento em estado de mais atenção para então procurar a que fim tal forma pode se relacionar - embora se mantenha aí sempre desinteressado ao nunca afirmar ter encontrado um fim, nunca fixando e determinando aquela forma. Essa condição ao mesmo tempo atenta ao que a forma intuída pode ser e desinteressada quanto ao que ela é torna-se plenamente possível quando observamos que "não é necessário sempre descortinar pela razão" (§10-14). Essa liberdade, que entendimento e imaginação se permitem, só acontece por não haver necessidade de se reconhecer sempre os objetos, encontrando para eles um conceito (empírico), tal como estamos habituados a fazer ao identificar o que as coisas são. É essa liberdade estética que se expressa na ideia estética.

Dentre as artes belas, talvez seja a arquitetura a arte que menos pode não deixar transparecer seu uso, destino, fim ou regra - uma tarefa justamente do gênio enquanto único capaz de criar uma arte livre ou bela. Mas nem por isso Kant vincula a arquitetura necessariamente a uma arte mecânica ou boa. É possível uma arquitetura como arte bela, porque as faculdades de conhecer podem operar livremente. Nesse sentido, tudo pode ser ajuizado como belo e aí está um ponto interessante e atual: podemos nos relacionar com o mundo de uma maneira a não determinar sempre, de modo a deixar haver sempre outra(s) possibilidade(s) na relação que construímos com o mundo. Abaixo pensamos duas situações que servem de parâmetro não como exemplo ou esquema (condições em que as faculdades da imaginação e entendimento trabalham na construção do conhecimento, empírico ou dos seus princípios), mas como da ordem daquilo que Kant entende como símbolo, de um procedimento reflexivo mais do que algo que possa ser transposto tal e qual entre as duas instâncias que estão supostas num exemplo ou esquema (cf. §59).

\section{Niemeyer tardio: Museu Nacional (2006) e a Torre Digital (2008-12)}

Escolhemos duas obras do contexto amplo da produção de Niemeyer: o Museu Nacional de Brasília e a Torre de TV Digital. Obras muito criticadas por arquitetos, críticos e por profissionais de museu. ${ }^{10}$ Não por isso as escolhemos, mas porque são casos em que a intenção política parece minimizada pelo próprio arquiteto. O Museu Nacional, na maioria dos casos, é criticado por ser uma arquitetura de baixa qualidade, isto é, uma arquitetura ruim, pois não seria apropriada para o fim a que se dispõe, grosso modo falando, um lugar para receber exposições, conferências ou sendo um lugar de encontro, lazer, diversão, e até mesmo um lugar para guardar obras, seguindo a proposta clássica do museu. Sabemos que essa função última é talvez a menor preocupação como parte da concepção do museu com características contemporâneas. Que características são 
essas? Quando observamos a ideia geral de Hélio Oiticica quanto ao fato de que 0 museu é o mundo, também podemos estar pensando de maneira clássica porque é no mundo onde todas as coisas são ou estão guardadas. Mas definitivamente não era isso que Oiticica imaginava, ele pensava na possibilidade de transformação das coisas em obras de arte desde uma liberdade ao mesmo tempo política e estética que permitiria uma criação conjunta da obra, da qual o espectador reassumiria um papel para além do gosto contemplativo nesse processo de reconhecimento das coisas como obras de arte interferindo nelas de algum modo (corporal, reflexivo, etc.). Ora, se o museu, de uma perspectiva contemporânea, abriga variados e impensáveis usos e destinos, se aproximando mesmo de como as coisas no mundo ganham e perdem sentido se transformando, esse museu teria de abrigar isso tudo e não apenas obras de arte prontas e reconhecidas pela história da arte. Pode e deve abrigar até obras, mas não somente isso, e aqui o museu se torna contemporâneo efetivamente. Porque ele passa a ter a possibilidade de, assim como as obras de arte, também (fazer) refletir sobre os sentidos que um museu pode assumir, desde que se admita ser possível uma tal transformação. O Museu Nacional de Brasília pensado por Niemeyer provoca essa política da liberdade sem cair numa crítica baseada ou contra ideologias.

Não que o Museu como obra possa ser objeto de um ajuizamento estético puro porque dê muito a pensar sobre os sentidos da arquitetura em geral, o que seria produzir obras para continuar produzindo obras, fomentando uma narrativa que orientaria se algo é ou não arte/arquitetura, permanecendo, assim, numa abordagem que dá primazia à consciência histórica (algo que toda obra de arte termina podendo ter!), seja levando em conta o diálogo entre estilos ou deixando de lado a importância dos estilos como algo superado. É que a arquitetura, aqui, faz pensar sobre os sentidos do museu também, e não sobre si mesma, sobre sua ligação com a história da arquitetura. Isso não a coloca como uma boa arquitetura, pois não cumpre necessária e eficientemente seus fins e destinos; nem como refletindo seu tempo, se quiséssemos recair numa abordagem baseada numa consciência histórica associada à noção de expressão vinculada a um suposto espírito do tempo. Não se trata tampouco de uma obra pensada como significado incorporado/corporificado como quis aproximar Danto sua filosofia da arte das ideias estéticas de Kant ${ }^{11}$, esquecendo que embora haja uma semelhança profunda por causa do caráter reflexivo das duas visões, a sua e a de Kant, uma é claramente discursiva e outra é claramente afetiva: meu prazer ao ajuizar como bela tal obra de Niemeyer me faz pensar no que pode ser um museu sem que jamais eu encontre um conceito de museu apropriado para as imensas possibilidades que tal forma me provoca a pensar e a fornecer uma unidade. Se seguíssemos Danto, teríamos uma afirmação ou uma sentença [aboutness] precisa sobre o museu, sobre o que ele é ou poderia ou ainda deveria ser, ou não. A intenção revelada (conteúdo ou sentido) apropriadamente no modo de apresentação da obra (seu material, lugar de exposição, relação com outras obras do entorno, contexto histórico ou político, etc.) transforma ordinariedade em obra de arte: transforma, no nosso caso, common place em arquitetura pensada como arte visual. 
Tal transformação efetiva pensada desde uma ideia estética (seguindo Kant) é algo impossível, porque por mais que eu relacione aquela forma apreendida pela imaginação a qualquer outra forma (entenda-se aqui conceito) de que o entendimento dispõe, jamais conseguirei completar essa conexão e realizar o processo de trans-formar, ou seja, de dar a uma forma outra. Simplesmente porque conseguindo completar, interrompo minha experiência estética do jogo livre das faculdades. Embora eu esteja, segundo Danto, ao fazer isso, justamente reconhecendo uma obra como obra de arte visual, sendo ela uma obra arquitetônica ou não. Se, ao dizer que o museu é o mundo, observo a abóbada cravada no chão e penso também no mundo como um museu não de lembranças, mas de coisas sem uma relação determinante com o passado e capazes de transformação (basta comparar o símbolo turístico do museu ao prédio do museu; ver slide 6), aí penso no Museu Nacional como sendo uma obra de arte visual, baseada na ontologia do significado incorporado. Teríamos aí, então, com Danto: "O museu é o mundo!".

Mas se penso nessa forma como podendo se relacionar ora a um mundo, ora ao nascimento ou morte do mundo quando observo a abóbada saindo ou entrando no chão, ora ao passeio que aquela bola gigante branca pode ter percorrido na Esplanada esbarrando nos outros monumentos até cair no buraco onde se encontra, ora me perguntando o que a lua faz no chão, etc., promovo uma liberdade que reforça a possibilidade de ver as coisas como podendo ser outras (sem me fixar em qualquer uma delas), e isso é um princípio forte da política e da liberdade. Com Kant, assim, teríamos não uma asserção [aboutness], tal como pressupõe um significado incorporado, mas uma interrogação sem resposta "o museu é o mundo?". Ou simplesmente "que é isso?", acompanhando o jogo que minhas faculdades de conhecer estabelecem quando estou ajuizando "isso é belo!" e me dirigindo ao Museu Nacional ou ainda à Torre Digital (2012) também em Brasília.

A flor de concreto armado que brotou do solo vermelho do Planalto Central é Brasília pensada metaforicamente enquanto sendo aquilo que Niemeyer viu ao lado de Lucio Costa na época da construção da cidade: a flor do deserto ${ }^{12}$ É uma brincadeira de copiar formas que não as suas como é comumente acusado Niemeyer quando visto como pouco criativo nos seus projetos mais recentes por repetir suas próprias criações? É uma ponte que leva da terra para as nuvens baixas nos dias em que as nuvens abaixam? É um mirante a 185 metros do chão e a quase 400 metros acima de Brasília, do qual vemos tudo circundante? É mesmo a torre de TV digital e internet como indicam as placas? Essas perguntas que vinculam a forma a um fim determinado guardam a possibilidade infinita e indeterminada de rever tal forma, porque não apresentam respostas. Guardam a liberdade de se relacionar de uma maneira diferente da usual com uma forma usual, no que a arquitetura interfere produzindo formas que são intervenções públicas por excelência, provocando, estimulando e lembrando a liberdade estética e a tarefa reflexiva.

\section{Pontos importantes e questões abertas nesta aproximação}


A liberdade vista aqui, de importância central tanto para Kant quanto para Niemeyer, pode ser resumida e orientada da seguinte maneira.

Liberdade estética em Kant: "não há sempre a necessidade de descortinar com a razão", ou seja, eu posso me relacionar com o mundo com o apoio de conceitos determinados, mas também posso abrir mão dessa relação e prestar atenção ao prazer de exercitar minhas faculdades sem fixar o quê das coisas: enquanto são ou devem ser. As formas belas contribuem para despertar essa relação diferente que as faculdades de conhecer conseguem estabelecer com o mundo, embora seja o jogo livre dessas faculdades a fonte desse prazer reflexivo. Quando Kant tenta associar tal prazer ao corpo (ou a efeitos corporais) pensa em um sensus vagus ${ }^{13}$, ou seja, no que seria o sentimento da liberdade (e da vida humana), no sentimento puro experimentado quando prestamos atenção ao que as coisas podem ser e ponto. A dimensão política implícita dessa liberdade é a de que mais de uma relação é possível com o mundo e com as pessoas, e depende de cada um estar atento a isso.

Liberdade política na arquitetura monumental de Niemeyer: desperta para algo inusitado, inesperado, provoca uma comparação entre a condição cotidiana e ordinária da qual fazemos parte, quando perguntamos pelo quê e o para quê das coisas como obras arquitetônicas; isso nos faz lembrar e apontar para outra condição possível (de conhecer, de existir, sentir, viver, etc.), lembrando que dispomos dessa possibilidade. A dimensão estética dessa liberdade, portanto, coincide exatamente com certa política: tornar-se consciente da existência cotidiana como capaz de transformação e enquanto podendo ser transformada.

A liberdade política, tal como pensamos acima na obra de Niemeyer, e aparentemente invisível nas obras tardias que escolhemos, surge para nós através de uma liberdade estética, de um sentimento da liberdade que Kant associa ao sentimento do belo. E essa liberdade estética aparentemente isenta de qualquer interesse é, como vimos também, base de uma liberdade política. Juntas, essas noções irmãs de liberdade sugerem uma política da liberdade pensada através de uma espacialidade que suaviza o componente sempre presente de uma narrativa histórica como a única possibilidade de acesso do/ao pensamento. ${ }^{14}$

\section{* Miguel Gally é professor de filosofia da UnB.}

${ }^{1}$ Projetos anteriores ao complexo da Pampulha, pelos quais Niemeyer foi (co)responsável, são também importantes para uma análise genealógica. Ver cronologia completa e detalhada no site da Fundação Oscar Niemeyer e no catálogo da exposição Oscar Niemeyer: Trajetória e produção contemporânea 1936-2008. Curitiba: Museu Oscar Niemeyer, 2008.'

2 Teóricos e críticos da arquitetura que não abrem mão da coerência do espaço construído tendo a eficiência do propósito como princípio ordenador da arquitetura quase sempre encontrarão motivos para rejeitar como ruins algumas obras de Niemeyer, assim como pouco criativas aquelas formas que podem ser identificadas em outras obras suas. Cf., p. ex., críticas da Revista Isto é, do New York Times e da Revista Especializada MDC, disponíveis em: 
Ver também David Underwood, por exemplo, que divide o conjunto da obra de Niemeyer considerando seu ponto mais criativo o conjunto do Memorial da América Latina (1987-9) em São Paulo e aponta a produção seguinte como tendo perdido em criatividade, sobretudo quanto à não descoberta de novas formas e combinações de formas, quando compara ao período anterior a 1989. UNDERWOOD, D. (1994) Oscar Niemeyer e o modernismo de formas livres no Brasil. São Paulo: Cosac Naify, 2003.

${ }^{3}$ Roger Scruton (1979) em Estética da arquitetura defende o caráter público da arquitetura como algo que a separa da escultura, se esta for entendida como simples expressão individual. Comparar essa idéia com uma das primeiras monografias escritas sobre Niemeyer: PAPADAKI, S. Oscar Niemeyer. New York: G.Braziller, 1960, livro que apresenta a contribuição pessoal e autoral de Niemeyer para a história da arquitetura.

${ }^{4}$ Niemeyer, O. A forma na arquitetura (1978). Rio de Janeiro: Renavam, 2005, pp. 27-32; "Os caminhos da arquitetura". In: Conversa de arquiteto. Rio de Janeiro: Renavam, 1993.

${ }^{5}$ Cf. DANTO, A. "Introduction”. In: Unnatural Wonders). N. York: FSG, 2005; After the End of Art. Princeton: PUPress, 1997, fim do capítulo 5, início do capítulo 11.

${ }^{6}$ A Praça dos Três Poderes (do Estado democrático) é um lugar deixado vazio, concebido para ser ocupado pelo homem em celebração a sua condição civil, livre, supostamente o centro da democracia, cujo quarto elemento, no caso de ser mesmo uma praça quadrilátera, seria a natureza e a linha do horizonte até que outros edifícios ocupassem a visão. De frente para o horizonte nascente, de costas para o Legislativo (Congresso Nacional), Executivo (P. Planalto) à esquerda, norte e Judiciário (STF) à direita, sul: no meio e de frente para a alvorada, o homem livre poderia seguir.

${ }^{7}$ KANT, I. Crítica da faculdade do Juízo. Tradução de Valério Rohden e Antonio Marques. Rio de Janeiro: Forense, 1994. Entre parênteses apenas o parágrafo de referência ou citação.

${ }^{8}$ KANT, I. Lógica (Jaesche). Tradução de Guido de Almeida. Rio de Janeiro: Tempo Brasileiro, s/d, p. 53. Associação direta feita entre juízo estético do agradável e a fantasia.

${ }^{9}$ Cf. GUYER, P. “Kant and Philosophy of Architecture”. In: JAAC, v. 69, 2011(Winter).

${ }^{10}$ Ver nota acima com as referências das críticas de jornal e revistas.

${ }^{11}$ Cf. DANTO, A. "Embodied Meanings, Isotypes, and Aesthetical Ideas". In: JAAC, v. 65, 2007 (Winter).

12 "Brasília foi para mim uma experiência extraordinária, vendo a cidade, que Lúcio projetou, crescer como uma flor do deserto naquela área vazia e solitária”. NIEMEYER, O. A forma na arquitetura. Op. cit., p. 45.

13 Tema trabalhado mais detalhadamente em GALLY, M. . "Kant and the Feeling of Life: On Pleasure and the Ambient of Beauty". In: X. Kant Kongress, 2008, São Paulo. Akten des $X$ Internationalen Kant-Kongresses. Berlin/N.York: Walter de Gruyter, 2008, v. III, pp. 623-630.

14 Este trabalho é fortemente complementado pela conferência "Kant e sua estética das arquiteturas entre fantasia e crítica" em publicação nas Atas do Colóquio Internacional Fantasia e Crítica; embora o item 2, em ambos, tenha o objetivo de apresentar o pensamento de Kant e, por isso, eles sejam muito parecidos. Agradeço a contribuição crítica dos membros da mesa Vladimir Vieira e Márcia Gonçalves, e ao interesse dos demais participantes do nosso grupo de trabalho, que, assim, me provocaram a continuar escrevendo sobre o tema. 